\title{
Development and Optimization of a Voltammetry Adsortive Method with Alizarine for Aluminium Determination in Water
}

\author{
Miriam Barquero Quirós* \\ Centro de Electroquímica y Energía Química y Escuela de Química, \\ Universidad de Costa Rica, Ciudad Universitaria Rodrigo Facio, Apartado 2060, Costa Rica
}

Received 31 May 2004; accepted in revised form 19 January 2005

\begin{abstract}
Some of the aluminium complexes are electroactive at positive potentials, being necessary a carbon vitreous electrode to their quantitative determination. Nevertheless the aluminium alizarine complex could be measured at negative potential with a mercury hanging electrode, but this complex is not electroactive at negative potential; instead of that, the residual alizarin non complex could be measured. The kinetic complex is very slow, so it is necessary to heat at $80{ }^{0} \mathrm{C}$, for five minutes. The study of experimental conditions of complex formation was established at $\mathrm{pH} 9.25$ and is determinant in the complex formation; besides, the buffers employed should be of high regulatory capacity to obtain derivative formation. The optimization of the measurement experimental conditions was done by square wave voltammetry (SWV). Detection limit got using standard deviation of seven blank solutions was $3 \mu \mathrm{g} / \mathrm{L}$, the variation coefficient was $8 \%$, and the mean recovery for $16 \mu \mathrm{g} / \mathrm{L}$ was $97 \%$. The calibration curves were done in a linear interval of 8 to $64 \mu \mathrm{g} / \mathrm{L}$. The method application to water samples is possible after previous evaporation.
\end{abstract}

Keywords: adsortive square wave voltammetry, alizarine, aluminium, experimental conditions, method optimization, tap water.

\section{Introducción}

El aluminio no se consideró toxico por años, pero su papel en la hemodiálisis está abundantemente documentado desde 1976 [1]. Algunos accidentes de contaminación han llamado la atención hacia el desarrollo de métodos para determinar aluminio en agua potable [2]. Los métodos adsortivos permiten alcanzar los bajos niveles de concentración necesarios para las determinaciones en agua potable por la formación de complejos solubles de aluminio con

\footnotetext{
* Corresponding author. E-mail address: mbarquero@ calzada.equi.ucr.ac.cr
} 
moléculas orgánicas del tipo de las antraquinonas, como la alizarina [3]. La adsorción de la alizarina a un electrodo de gota de mercurio permite su determinación cuantitativa, ya que la disminución de la corriente de la alizarina es proporcional a la concentración de aluminio.

El aluminio se ha estudiado durante años por diversas técnicas, siendo las más conocidas las determinaciones por absorción atómica con llama o con horno de grafito [4].

La determinación directa del aluminio es difícil por su posición electroquímica, por lo tanto es preferible la formación de complejos de aluminio electroactivos en el ámbito de trabajo de un electrodo de Hg. Las técnicas voltamperómetricas adsortivas más recientes han permitido obtener límites de detección más bajos aplicables a muestras medio ambientales con bajas concentraciones [5]. También se ha estudiado la especiación del aluminio en aguas naturales generando complejos con violeta de solocromo [6]. Se aplicó el método polarógrafico a la determinación indirecta de aluminio con alizarina [7]. Otras técnicas voltamperómetricas más sensibles utilizan la formación y adsorción de complejos de aluminio, sobre electrodos de mercurio de gota suspendida [8]. También se utilizan electrodos de grafito [9]. La formación de los complejos de aluminio en ambos casos es dependiente de ámbitos estrechos de pH. En esta investigación se optimizaron las condiciones experimentales y de medida para la formación del complejo de aluminio con alizarina y se relacionó la disminución de la corriente del pico electroactivo de la alizarina con la concentración de aluminio adicionada.

El objetivo propuesto fue desarrollar y validar un método para que permitiera cuantificar aluminio en agua potable.

\section{Parte experimental}

Se utilizó un polarógrafo E\&G PARC modelo 384 B, acoplado a un graficador Houston y a un sistema de tres electrodos E\&G modelo $303 \mathrm{~A}$, con un electrodo de plata/cloruro de plata como referencia y un electrodo de platino como auxiliar; el electrodo de trabajo fue de gota suspendida de $\mathrm{Hg}$.

Toda la cristalería utilizada se colocó en baño de $\mathrm{HNO}_{3}$ al $20 \%$ v/v y se enjuagó con abundante agua de un sistema Milli Q.

Los reactivos usados para preparar los buffers fueron $\mathrm{NH}_{3}$ y $\mathrm{NH}_{4} \mathrm{Cl}$ de calidad suprapur de la casa Merck. Se usó un buffer $0.28 \mathrm{~mol} / \mathrm{L}$ en $\mathrm{NH}_{3}$ y $0.05 \mathrm{~mol} / \mathrm{L}$ en $\mathrm{NH}_{4} \mathrm{Cl}$; el pH del buffer empleado se ajustó con ayuda de un pHmetro a 9.25 con $\mathrm{HCl}$ destilado sobre cuarzo. La alizarina utilizada fue de calidad reactivo de la casa Sigma y se disolvió en etanol HPLC y $\mathrm{NH}_{3}$ de calidad suprapur al 1\%. Se utilizó un Tritrisol de $1000 \mathrm{mg}$ de la casa Merck para preparar la disolución patrón de aluminio.

La metodología propuesta para cuantificar aluminio comprendía la previa formación del complejo con alizarina, la adsorción sobre el electrodo de gota de mercurio de la alizarina residual y la desorción y medida de la corriente producida por la reducción de la alizarina que no se acomplejó con aluminio. 
Se realizó una optimización de las condiciones experimentales de medición, se determinaron los límites de detección y cuantificación del método, el coeficiente de variación, se realizó un estudio de recuperación y se determinó el pH óptimo para la formación del complejo aluminio-alizarina. La optimización de los parámetros experimentales se realizó, adicionando $20 \mu \mathrm{L}$ de una disolución de alizarina $0.2 \mathrm{~mol} / \mathrm{L}, 1 \mathrm{~mL}$ de buffer de $\mathrm{pH} 9.25$, con una concentración final de $20 \mu \mathrm{g} / \mathrm{L}$ de aluminio. Se calentó a $80 \pm 2{ }^{\circ} \mathrm{C}$ por 5 minutos y se aforó en balones de $25.00 \mathrm{~mL}$. Posteriormente se hicieron variar los parámetros de medición para determinar los valores a los cuales la corriente de la alizarina residual era mayor.

Se procedió a recristalizar la alizarina de $\mathrm{MeOH}$ /acetona/agua, y $\mathrm{MeOH}$ /agua, pero el sólido obtenido no generó ningún complejo con el aluminio, debido a que según se reporta, recristaliza como hidrato, por lo que se revolvió usar el sólido sin recristalizar, y se preparó una disolución madre de alizarina $2 \times 10^{-4}$ molar, de la que se diluyeron $20 \mu \mathrm{L}$ a $25.00 \mathrm{~mL}$.

Para generar el complejo, se colocaron en balones de $25,00 \mathrm{~mL}$, blancos que contenían $1,00 \mathrm{~mL}$ de buffer de $\mathrm{pH} 9.25,20 \mu \mathrm{L}$ de alizarina $2 \times 10^{-4}$ molar y 20 $\mu \mathrm{g} / \mathrm{L}$ de alumnio; para la curvas de calibración se adicionó aluminio en concentraciones de 8-64 $\mu \mathrm{g} / \mathrm{L}$, se calentó por 5 minutos en un baño a $80^{\circ} \mathrm{C}$. Se midió la corriente por la técnica SWV.

Las medidas se realizaron restando a la señal de la disolución blanco de alizarina y buffer, la señal correspondiente después de adicionar una cantidad exactamente conocida de una disolución patrón de aluminio; por este procedimiento se realizaron las curvas de calibración y las recuperaciones.

Los resultados de algunos parámetros experimentales optimizados se muestran en el apartado siguiente.

\section{Resultados y discusión}

Se procedió a seleccionar entre la técnica voltamperométrica de diferencial de pulso y onda cuadrada, en el modo adsortivo encontrándose que la onda cuadrada era 100 veces mas sensible que la técnica de diferencial de pulso.

Se procedió a determinar el $\mathrm{pH}$ apropiado para la reacción, generando el complejo de aluminio-alizarina a 4 valores de $\mathrm{pH}$, adicionando a la alizarina diferentes buffers y además $20 \mu \mathrm{g} / \mathrm{L}$ de aluminio y se encontró que un $\mathrm{pH}$ entre 9.25-9.50 era el adecuado para la reacción. A este $\mathrm{pH}$ se producía una diferencia notable entre la señal de la alizarina libre y acomplejada con el aluminio; ya que la alizarina al acomplejar el aluminio disminuye su señal al mismo potencial, debido a que el complejo de aluminio-alizarina no es electroactivo. Se seleccionó el $\mathrm{pH}$ de 9.25 donde la disminución de la señal era mayor y la forma del pico era definida. Se procedió luego a preparar una serie de disoluciones reguladoras de diferentes concentraciones, con los que se prepararon y midieron diferentes curvas de calibración, encontrándose que las disoluciones reguladoras muy diluidas, aun a $\mathrm{pH}$ de 9.25 no generaban el complejo. Debido a que los balones se lavan en baños ácidos, se debe usar un buffer muy concentrado que al diluir a $25 \mathrm{~mL}$ fuera $0.28 \mathrm{~mol} / \mathrm{L}$ en $\mathrm{NH}_{3}$ y $0.05 \mathrm{~mol} / \mathrm{L}$ en $\mathrm{NH}_{4} \mathrm{Cl}$, para regular el $\mathrm{pH}$. Se encontró que a un $\mathrm{pH}$ inferior a 9 la reacción de acomplejación no 
ocurre, en contraste con lo reportado en trabajos previos donde se dice que el aluminio-alizarina se acomplejan en un ámbito de pH 7.5 -10.5 [7]. La señal fue estable hasta dos días después de la formación del derivado, las disoluciones se almacenaron en oscuro antes y después del proceso de medida. Los resultados de las determinaciones de $\mathrm{pH}$ realizadas se muestran en la Tabla 1.

Tabla 1. Selección del pH de formación del complejo aluminio-alizarina.

\begin{tabular}{ccccc}
\hline $\mathrm{pH}$ & $\begin{array}{c}\text { Corriente } \\
\text { alizarina } \\
(\mathrm{nA})\end{array}$ & $\begin{array}{c}\text { Potencial } \\
(\mathrm{V})\end{array}$ & $\begin{array}{c}\text { Corriente de alizarina } \\
+20 \mu \mathrm{g} / \mathrm{L} \mathrm{de} \mathrm{Al}(\mathrm{nA})\end{array}$ & $\begin{array}{c}\text { Potencial } \\
(\mathrm{V})\end{array}$ \\
\hline 6.48 & 24124 & 0,704 & 13380 & 0.592 \\
8.05 & 7560 & 0.724 & 15870 & 0.708 \\
9.25 & 2150 & 0.788 & 1410 & 0.796 \\
10.88 & 825 & 0.732 & 4320 & 0.556 \\
\hline
\end{tabular}

Se procedió luego a determinar las condiciones experimentales bajo las cuales la señal obtenida en SWV (onda cuadrada) era mayor. Se identificó el potencial al cual la alizarina en un buffer de $\mathrm{pH} 9.25$ disminuye su señal de forma proporcional con la concentración de aluminio, siendo este cercano a $0.8 \mathrm{~V}$. Se optimizaron los parámetros instrumentales en forma secuencial para la SWV cuyos valores se muestran en Tabla 2.

Tabla 2. Condiciones experimentales optimizadas para SWV.

\begin{tabular}{|l|c|}
\hline Potencial de acumulación & $0.500 \mathrm{~V}$ \\
\hline Tiempo de acumulación & $60 \mathrm{~s}$ \\
\hline Tiempo de equilibrio & $10 \mathrm{~s}$ \\
\hline Frecuencia y velocidad de barrido & $400 \mathrm{mV} / \mathrm{s}$ \\
\hline Altura de pulso & $0.040 \mathrm{~V}$ \\
\hline Tiempo de desoxigenación & $200 \mathrm{~s}$ \\
\hline Tiempo de purga entre réplicas & $20 \mathrm{~s}$ \\
\hline
\end{tabular}

La Fig. 1 muestra la variación de la corriente con el tiempo de equilibrio; se seleccionó un valor de 10 segundos debido a la técnica empleada y a la forma de la señal. En la Fig. 2 se muestra la variación de la corriente con la velocidad de barrido; el valor escogido fue $400 \mathrm{mV} / \mathrm{s}$. Con esta velocidad de barrido, la forma del pico era definida. En la Fig. 3 se muestra la variación del potencial de acumulación con la corriente. Este parámetro es el que determina la adsorción de alizarina al electrodo; el potencial se mantiene constante entre $-0.2 \mathrm{~V}$ y $-0.5 \mathrm{~V}$. Se seleccionó un valor de $0.5 \mathrm{~V}$ debido a que esto hacía la determinación más rápida al disminuir el barrido del potencial. 


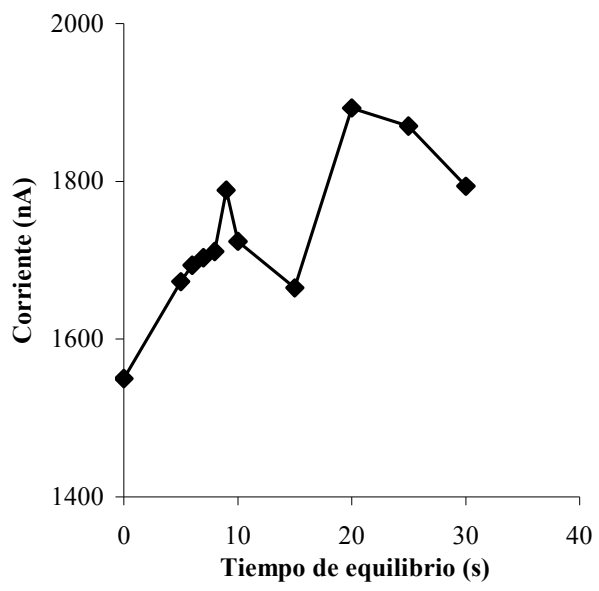

Figura 1. Variación de la corriente de alizarina con el tiempo de equilibrio.

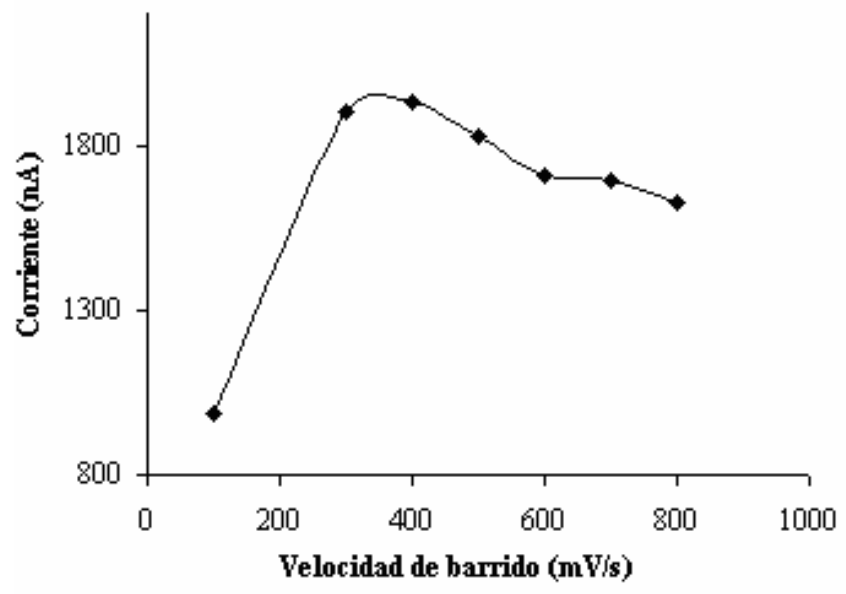

Figura 2. Variación de la corriente de alizarina con la velocidad de barrido.

En la Fig. 4 se muestra el efecto del tiempo de acumulación a -0.5 V; no se llegó a la saturación de la gota porque con ese tiempo de acumulación la señal de corriente era del orden de $2 \times 10^{3} \mathrm{n} \mathrm{A}$.

Se encontró que el tiempo de desoxigenación era crítico, porque la señal se disminuía al no pasar suficiente nitrógeno. Un tiempo inicial de purga de 200 segundos fue adecuado para producir una señal definida y economizar el nitrógeno empleado para desoxigenar $\mathrm{y}$ disminuir el tiempo entre determinaciones independientes. 


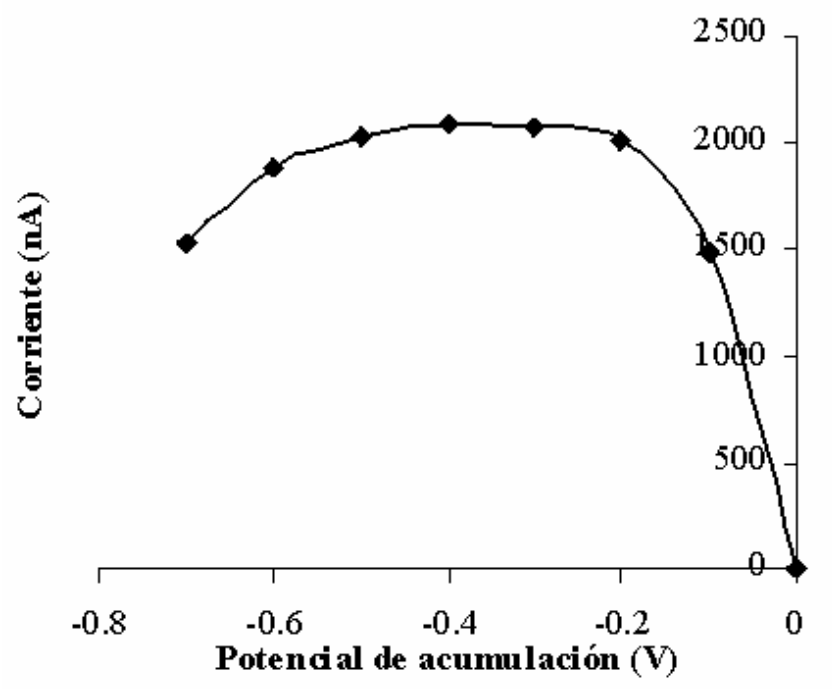

Figura 3. Variación de la corriente de alizarina con el potencial de acumulación.

Con estas condiciones, se procedió a realizar un estimado preliminar del límite de detección calculado como tres veces la desviación estándar en concentración del blanco. Se calcularon también el límite de cuantificación, la veracidad, el coeficiente de variación y la linealidad [10].

Estos parámetros de desempeño del método se muestran a continuación en la Tabla 3.

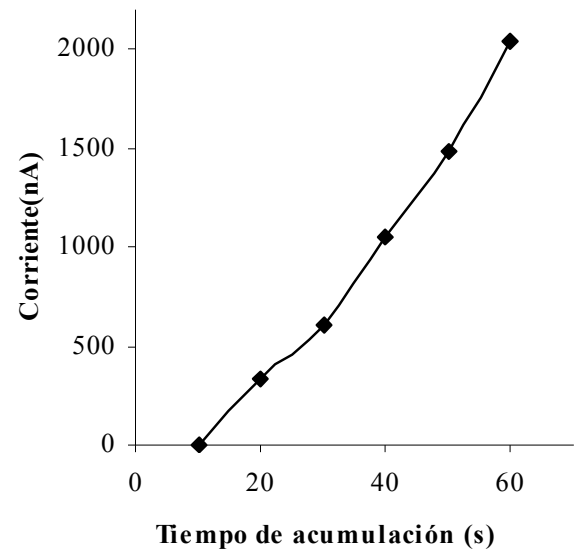

Figura 4. Variación de la corriente de alizarina con el tiempo de acumulación. 
Tabla 3. Parámetros de desempeño del método aluminio alizarina.

\begin{tabular}{|l|c|}
\hline Límite de detección & $3 \mu \mathrm{g} / \mathrm{L}$ \\
\hline Límite de cuantificación & $10 \mu \mathrm{g} / \mathrm{L}$ \\
\hline Desviación estándar del blanco & $1 \mu \mathrm{g} / \mathrm{L}$ \\
\hline Coeficiente de variación de blancos $(\mathbf{n}=\mathbf{7})$ & $8 \%$ \\
\hline Recuperación de $\mathbf{1 6} \boldsymbol{\mu g} / \mathbf{L}$ & $97 \%$ \\
\hline Coeficiente de variación de $\mathbf{1 6} \boldsymbol{\mu g} / \mathbf{L}(\mathbf{n}=\mathbf{7})$ & $17 \%$ \\
\hline Ámbito lineal & $10-70 \mu \mathrm{g} / \mathrm{L}$ \\
\hline
\end{tabular}

Se muestra en la Fig. 5 la disminución de la señal de alizarina al adicionar concentraciones crecientes de aluminio. La disminución de la señal se relaciona con la concentración creciente de aluminio, como se observa en la Fig. 6.

La derivatización con muestras de agua potable se probó, pero cuando fueron medidas se encontró que no se había generado el complejo de aluminio-alizarina, dado que no eran significativamente diferentes del blanco, posiblemente porque al diluir demasiado el buffer no mantiene su capacidad reguladora; la reacción con los patrones de aluminio se realizó en volúmenes menores a $1.5 \mathrm{~mL}$, por lo que se aconseja evaporar las muestras de agua potable antes de proceder a la formación del complejo de aluminio-alizarina.

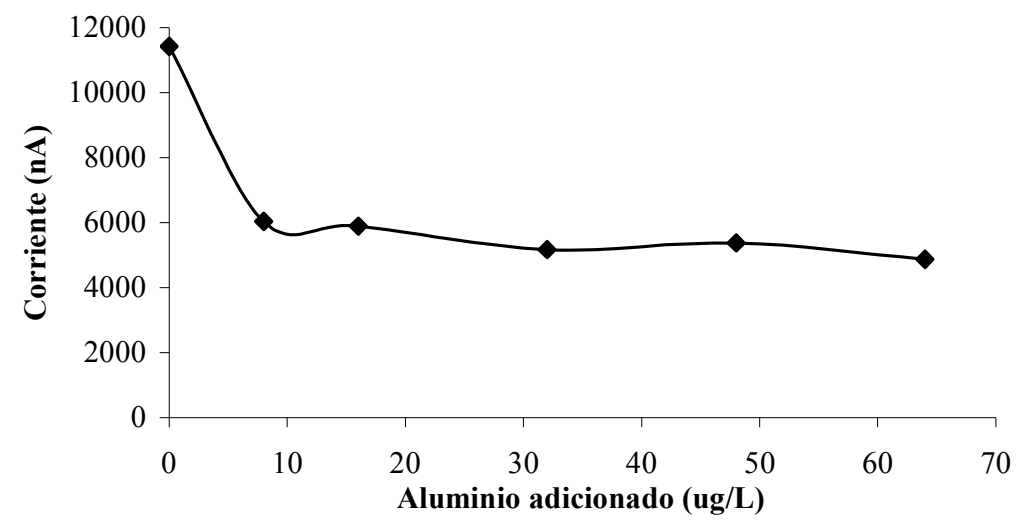

Figura 5. Disminución de la corriente de alizarina al adicionar aluminio. 


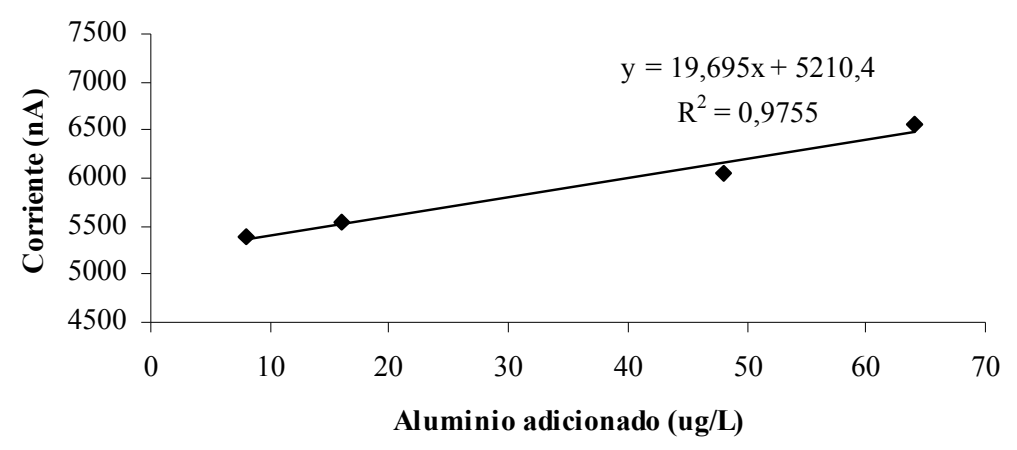

Figura 6. Linealidad de la disminución de la señal del blanco de alizarina con la concentración de aluminio.

La alizarina disuelta en $\mathrm{NH}_{3}$ y en buffer de $\mathrm{pH} 9.25$ fue estable por un mes aproximadamente: se debió preparar cada vez que una disolución anterior no acomplejaba el aluminio. Esto hace que al preparar nuevas disoluciones de alizarina, las medidas de los blancos cambien de un bache a otro de alizarina, por lo que se determinó la diferencia entre la alizarina adicionada y la alizarina restante después de adicionar diferentes concentraciones de aluminio. Se procedió a determinar la recuperación del método encontrándose que la recuperación promedio cuando se adicionaron $16 \mu \mathrm{g} / \mathrm{L}$ fue de $97 \%$ con un coeficiente de variación de $17 \%$.

Se debe señalar en este método, que presenta un coeficiente de variación apropiado para el nivel de concentración medido, pero que el hecho de medir por diferencia entre el blanco y los patrones acumula el error, esto lo hace menos sensible. La derivatización de muestras sólo se puede obtener al evaporar, porque una dilución alta del buffer hace que se venza la capacidad reguladora; por otra parte una mayor cantidad de buffer aumentará la concentración de aluminio de los blancos, por lo que para aplicarlo a las muestras de agua potable es necesario evaporar casi hasta sequedad.

Los límites de detección y cuantificación obtenidos son adecuados para el análisis de bajas concentraciones de aluminio, el coeficiente de variación es apropiado, así también la veracidad del método, el derivado formado es muy estable, de acuerdo a lo reportado.

Es también destacable que este es un método menos susceptible a la contaminación, debido a que el derivado sólo se forma a $80{ }^{0} \mathrm{C}$, por lo que la contaminación por el aluminio externo a los balones donde se realizan las curvas de calibración es menos probable. Este complejo del aluminio proporciona resultados precisos como se requiere para un método analítico en este nivel de concentración, pero no son robustos; con respecto al $\mathrm{pH}$, la reacción a un $\mathrm{pH}$ inferior a 9, no ocurre del todo, por lo que el control del pH es muy estricto, entre 9.25 y 9.50. El pH se midió con un pHmetro en las disoluciones que no presentaban disminución de la señal del blanco y se encontró en todos los casos donde no se formó el complejo inferior a 9. 
Las determinaciones en onda cuadrada también son mucho más rápidas que otras técnicas voltamperométricas.

\section{Agradecimientos}

Se agradece a la Vicerrectoría de Investigación, a la Escuela de Química y al Centro de Electroquímica y Energía Química (CELEQ), de la Universidad de Costa Rica, por el apoyo prestado a este proyecto.

\section{Desarrollo y Optimización de un Método Voltamperométrico Adsortivo con Alizarina para la Determinación de Aluminio en Aguas}

\section{Resumen}

Algunos complejos de aluminio son electroactivos a potenciales positivos, siendo necesario un electrodo de carbón vítreo, para su determinación cuantitativa. Sin embargo el complejo de aluminio con alizarina se puede medir a potencial negativo, con un electrodo de mercurio de gota suspendida; el complejo de aluminio-alizarina no es electroactivo, y la alternativa es medir la alizarina residual después de la formación del complejo con aluminio, cuya cinética es muy lenta y debe calentarse 5 minutos a $80^{\circ} \mathrm{C}$. Se procedió al estudio de las condiciones experimentales bajo las cuales se forma el complejo aluminio con alizarina, siendo el $\mathrm{pH}$ de 9.25 determinante; asimismo se encontró que el buffer debía ser de alta capacidad reguladora para obtener la formación del derivado. Se realizó la optimización de las condiciones experimentales de medición por la técnica de voltamperometría de onda cuadrada (SWV).

El límite de detección obtenido a partir de la desviación estándar de 7 blancos fue $3 \mu \mathrm{g}$ $/ \mathrm{L}$, y el coeficiente de variación $8 \%$, la recuperación promedio para $16 \mu \mathrm{g} / \mathrm{L}$ fue de 97\%. Las curvas de calibración se realizaron en un ámbito de 8 a $64 \mu \mathrm{g} / \mathrm{L}$. La aplicación del método a muestras de agua es posible mediante la previa evaporación de las mismas.

Palabras clave: voltamperometría adsortiva, alizarina, aluminio, condiciones experimentales, optimización método, agua potable.

\section{Referencias}

1. C.A. Alfrey, Advances in Clinical Chemistry, Vol 3, Academic Press, Inc., USA. 1983, 69-91.

2. P. Altman, J. Cunningham, U. Dhanesha, M. Ballard, J. Thompon, F. Marsh, Brit. Med. J. 319 (7213) (1999) 807- 811.

3. A.Z. Abu Zuhri, W. Voelter, Fresenius J. Anal. Chem. 360 (1998) 1-9.

4. A. Romero, J. Tahán, A. Moronta, Anal. Chim. Acta 257 (1992) 147-154.

5. J. Wang, J. Lu, R. Setiadji, Talanta 40-3 (1993) 351-354.

6. $\quad$ X. Wang, J. Lei, S. Bi, N. Gan, Z. Wei, Anal. Chim. Acta 449 (2001) 35-44.

7. M. Kapel, W.D. Selby, Talanta 16 (1969) 915-920.

8. C. Li, B.D. James, R.J. Magee, Microchim. Acta II (1989) 149-156.

9. Q. Cai, S.B. Khoo, Anal. Chim. Acta 276 (1993) 99-108.

10. J.K. Taylor, Quality Assurance of Chemical Measurements, Lewis Publisher Inc., USA, 159-163. 